NBER WORKING PAPER SERIES

\title{
SACRED VALUES? THE EFFECT OF INFORMATION ON ATTITUDES TOWARD PAYMENTS FOR HUMAN ORGANS
}

\author{
Julio J. Elias \\ Nicola Lacetera \\ Mario Macis \\ Working Paper 20866 \\ http://www.nber.org/papers/w20866
NATIONAL BUREAU OF ECONOMIC RESEARCH
1050 Massachusetts Avenue
Cambridge, MA 02138
January 2015

We thank the participants to the ASSA 2015 Meetings session on Moral Values and Economic Behavior for their comments. Financial support from the Research and Scholarly Activity Fund of the University of Toronto - Mississauga is gratefully acknowledged. This randomized controlled trial was registered in the American Economic Association Registry for randomized control trials under Trial number 0000540. The views expressed herein are those of the authors and do not necessarily reflect the views of the National Bureau of Economic Research.

NBER working papers are circulated for discussion and comment purposes. They have not been peerreviewed or been subject to the review by the NBER Board of Directors that accompanies official NBER publications.

(C) 2015 by Julio J. Elias, Nicola Lacetera, and Mario Macis. All rights reserved. Short sections of text, not to exceed two paragraphs, may be quoted without explicit permission provided that full credit, including $(\odot$ notice, is given to the source. 
Sacred Values? The Effect of Information on Attitudes toward Payments for Human Organs

Julio J. Elias, Nicola Lacetera, and Mario Macis

NBER Working Paper No. 20866

January 2015

JEL No. D47,D60,H80,I19,K32,Z10,Z18

\begin{abstract}
$\underline{\text { ABSTRACT }}$
Many economic transactions are prohibited-even in the absence of health or safety concerns or negative externalities-because of ethical concerns that cause these exchanges to be perceived as "repugnant" if conducted through a market. Establishing a system of payments for human organs is a particularly relevant example given its implications for public health; in almost all countries, these payments are prohibited because they are considered morally unacceptable - a prohibition that societies seem to accept despite the long waitlists and high death rates for people needing a transplant. We investigate how deeply rooted these attitudes are and, in particular, whether providing information on how a price mechanism can help alleviate the organ shortage changes people's opinions about the legalization of these transactions. We conducted a survey experiment with 3,417 subjects in the U.S. and found that providing information significantly increased support for payments for organs from a baseline of $52 \%$ to $72 \%$, and this increase applied to most of the relevant subgroups of the analyzed sample. Additional analyses on the support for other morally controversial activities show that attitude changes in response to information depend on the type of activity under consideration and interactions with other beliefs.
\end{abstract}

Julio J. Elias

Av. Córdoba 374

(C1054AAP) Ciudad de Buenos Aires

Argentina

je49@cema.edu.ar

Nicola Lacetera

University of Toronto

105 St. George Street

Toronto, ON M5S 2E9

Canada

and NBER

nicola.lacetera@utoronto.ca
Mario Macis

Johns Hopkins University

Carey Business School

100 International Dr.

Baltimore, MD 21202

mmacis@jhu.edu

A Replication file archive is available at:

http://www.nber.org/data-appendix/w20866 


\section{Introduction}

In most modern societies, a number of economic transactions are prohibited or severely restricted. Although the reasons for the restrictions are often related to health or safety issues, some transactions are prohibited due to ethical concerns or because they are perceived as repugnant. That is, even when transacting parties may be willing to engage in the trade, third parties oppose the idea of that exchange occurring in the marketplace, and thus prohibit it. These limits vary over time and places. For example, indentured servitude was once accepted in many countries, but is now universally considered unacceptable and banned. Conversely, life insurance contracts were considered repugnant in the past but are now widely allowed (Zelizer 1979). Varied activities such as same-sex marriage, surrogacy, prostitution, the supply of cadavers for research or eating certain types of food (e.g., horse meat) are regulated differently in different countries-and sometimes even within the same country - mostly because of different moral considerations (Roth [2007, 2014], Anteby 2010).

The heterogeneities and changes over communities, in particular, reveal that repugnance-based prohibitions often derive from deeply-held, shared values that contribute to tying societies together, are transmitted over generations, and affect economic outcomes (Alesina and Giuliano, forthcoming; Bisin and Verdier 2010; Guiso, Sapienza and Zingales 2006).

Repugnance-based prohibitions on some transactions, however, have important implications for social welfare. This paper focuses on one such transaction: payments for human organs for transplantation. In the United States alone, more than 120,000 people are on the waiting list for an organ transplant. Every year, only about 29,000 transplants are performed, and over 10,000 people die while waiting for an organ or leave the waiting list because they are too sick for a transplant. The average wait time for a kidney transplant is about 4.7 years, up from 2.9 years only a decade ago (Becker and Elías 2014, based on data from UNOS 2014). The cost of supply shortages is also given by the financial burden of alternative procedures, such as dialysis in the case of kidneys, which have an estimated cost of $\$ 250,000$ per patient (Matas and Schitzler 2003).

In light of these facts, it is not surprising that there is increasing interest in devising strategies to reduce the organ supply shortage. In particular, some scholars have identified the prohibition of monetary payments as one of the main reasons for the large gulf between demand and supply of organs. According to recent estimates, payments between $\$ 15,000$ and $\$ 30,000$ would be sufficient to "clear the market" for kidneys (Becker and Elías 2007). Yet, under current legislation, transfers of human organs "for valuable consideration" are prohibited in the United States. Ethical considerations and repugnance factors play a large role in the debate about the use of a price mechanism to increase 
the supply of organs. For example, the design of organ exchanges through chain matches was devised in a way to avoid the ethical objections typically associated with monetary payments (Roth [2007, 2014] Roth et al. 2004). In contrast, proposals in favor of regulated payments for organs (Becker and Elías 2007, Gaston et al. 2006) have long received strong opposition. The objections are not limited to such concerns as exploitation of the poor and coercion, which could in principle be mitigated by appropriate policy design (Becker and Elías 2014), but include reference to "inalienable values" and "fundamental truths" (Delmonico et al. 2002); the definitive words often used suggest that keeping these transactions out of the marketplace is considered a "protected value"-i.e., a value that people are unwilling to trade off no matter what the costs of doing so may be (Baron and Spranca 1997). In fact, arguments against payments for organs often acknowledge the potential benefits of allowing such trades; yet the moral basis of the opposition is considered strong enough to forego those benefits (Delmonico et al. 2002; Sandel 2012). These and other considerations have sparked scholarly debates and have also reached popular news outlets. ${ }^{1}$

Although at any given time we may know what transactions are considered repugnant (and where), there is limited understanding of the determinants of the repugnance towards a transaction and of whether and how this changes over time. In recent years, in particular, the increased availability of data and more reliable research methods have improved scholars' ability to test or estimate whether allowing the use of incentives (monetary or non-monetary) for certain transactions leads to positive outcomes such as increased supply of safe blood (Lacetera, Macis and Slonim 2013) or organs (Becker and Elías 2007); better health outcomes, changes in the prevalence of previously illegal activities (Cunningham and Shah 2014), increased tax revenues, and so on.

In this paper, we study whether empirical evidence and, more broadly, information on the effectiveness of different ways to increase the supply of human organs for transplantation (based on scientific research) affect attitudes toward allowing payments for organs, or, instead, anti-market attitudes reflect values that cannot be sacrificed. The answer to this question has important implications. First, it improves our understanding of the nature of moral beliefs about markets. Second, it illuminates which policy levers are available for market design to solve pressing social problems, and which are not because the majority of citizens oppose them. Third, it sheds light on whether seemingly deep attitudes are affected by new evidence about the costs and benefits associated with choices that, at a given time, are considered unethical (Gibson et al. 2013). Finally, it contributes to the current debate as to whether at least some ethical principles can (or should) be

\footnotetext{
${ }^{1}$ See for example Volume 40, Issue 3 (March 2014) of the Journal of Medical Ethics for article on the topic, as well as American Society of Transplantation (2014), Becker and Elias (2014), and New York Times (2014).
} 
evidence-based (Stretch 2008, Leget et al. 2009, Molevich et al. 2014, Heath 2012), and how cognition is affected by individual beliefs (Kahan 2003).

On the one hand, studies have shown that some strongly held values may change when individuals are asked to consider specific applications rather than broad principles, or think about counterexamples and how to resolve conflicts between these values (Maio and Olson 1998, Seligman and Katz 1996, Baron and Leshner 2000). On the other hand, because of the strong nature of views opposing payments for organs, it is not obvious that additional information on the potential effectiveness of these transactions would change attitudes in this specific case. In fact, some research even showed that providing additional information, for example on the safety of a vaccine, might lead individuals who are initially more skeptical about that treatment to become even less willing to receive it, even if they trust the provided information (Nyhan and Reifler 2014; Nyhan et al. 2014).

We also explore whether the likelihood that attitudes change in response to new evidence depends on individual characteristics such as gender, religion, education, income, or political views. Because views about payments for organs are potentially driven by other ethical beliefs, one might expect that other individual features, such as gender, and other dimensions through which beliefs manifest themselves, such as political views and religiosity might interact with the way information is read, processed, interpreted, and acted upon. Studies show, for example, that political views might affect mathematical problem-solving abilities of individuals, according to how the problem is framed and the political beliefs of a subject (Kahan et al. 2011). Moreover, income or education might be correlated with the pre-existing level of information and awareness, therefore potentially affecting the degree to which a given piece of information affects opinions.

The study was conducted through an online survey experiment with respondents residing in the United States. Subjects were randomly assigned to treatment and control conditions. The subjects in the treatment group received a short reading (approximately 500 words) describing the current state of organ shortage in the United States and its consequences in terms of human lives lost, long wait lists, and high financial costs. The text then reported on a few different strategies that have been proposed (and in some case implemented) to alleviate the shortage, including kidney exchanges, changing the default rule for cadaveric organ donation, as well as regulated payments to donors or their families, with references to the academic studies that have evaluated these proposals (Beard and Osterkamp 2013, Becker and Elías 2007). To encourage them to carefully read the text, the subjects were informed that a comprehension question would follow. Finally, the subjects completed survey questions; the first of these questions involved reporting their opinions about whether they would favor the implementation of regulated payments for organ donors or their families. Because of the 
sensitivity of these issues, this question was framed according to the Item Count Technique (or "list experiment") in order to preserve the privacy and anonymity of the responses and to limit social desirability bias, which previous studies have shown can affect responses to "socially charged" questions (Coffman et al. 2013, Miller 1984). The control group received neither the text to read nor the comprehension question, and was only asked about support for payments for organs. The other survey questions, common to all treatments, concerned different socio-economic characteristics of the subjects. Our experimental design allows us to assess whether the approval for payment for organs-a transaction that has long been considered repugnant- is affected by the provision of scholarly and verifiable information about potential benefits, in terms of alleviation of the supply shortage and cost reduction, of this market-based solution. We also conducted a set of additional analyses to corroborate our interpretation of the findings.

The next Section illustrates the conceptual framework that guided our study, and describes the experimental design. The findings are in Section 3; a discussion and concluding remarks are in Section 4.

\section{Conceptual framework and research design}

\subsection{Conceptual framework}

Figure 1 offers a graphical representation of the simple conceptual framework that guided our experimental design and analysis. Line $A B$ is a hypothetical "frontier" of combinations of moral controversy and efficiency associated to different ways to establish and regulate a transaction; in the case of organs for transplant, these different ways include presumed consent default rules and payment for organs, among others. We assume that there is agreement on the "ranking" of the level of moral controversy for different institutional choices; for example, payments to those providing their organs for transplant is considered more ethically controversial than kidney exchanges, which in

turn are more controversial than a purely altruistic system of organ supply. ${ }^{2}$ The case where there is a trade-off between efficiency and ethical controversy (i.e., $A B$ is upward sloping) is the interesting one: greater efficiency (e.g., more lives saved) can be achieved only by means of mechanisms associated with higher moral controversy (e.g., a market for organs). We assume that efficiency enters as a good in the individuals' utility functions, whereas ethical controversy is a bad. If all solutions were ethically charged to the same extent, an individual would prefer the least controversial

\footnotetext{
${ }^{2} \mathrm{We}$ are making the frontier line continuous for convenience.
} 
combination. The indifference curves in the figure are upward sloping, with curves more toward the upper left corner corresponding to higher utility.

New information about the efficiency of a payment system can be modeled as an outward shift of the part of the frontier that has a higher level of moral controversy, such that the new frontier is $A C D$; that is, individuals now know that adopting certain morally controversial mechanisms would generate greater efficiency gains compared to what was previously thought. For example, suppose that a pilot study shows that monetary payments systematically attract more healthy donors. If preferences are such that there is a high rate of substitution between efficiency and level of ethical controversy, individuals are willing to relax their previously held moral rule (i.e., accept a more morally controversial solution) only if this produces large increases in efficiency (or they are willing to sacrifice high efficiency for even a small reduction in moral controversy); the indifference curves $b$ and $b^{\prime}$ depict this case. Less steep curves imply lower rates of substitution (curves $a$ and $a^{\prime}$ ). If attitudes toward paying for organs are closer to the former type of preferences, then new information on the higher enhanced efficiency of price-mediated mechanisms should not change the support for these activities $\left(r_{b} *\right.$ is the utility-maximizing level of repugnance for individuals with indifference curves of type $b$ under both the $\mathrm{AB}$ and the ACD frontiers). Conversely, individuals who are more willing to trade off moral acceptance and economic efficiency would respond to the new information by choosing a policy option that is more ethically charged; for example, for individuals with type $a$ preferences, the newly chosen level of moral controversy is $\left.r_{a}{ }^{\prime}>r_{a}{ }^{*}\right)$. Similarly, if a given society is currently adopting a particular solution, for example corresponding to point $C$ on the frontier, individuals with preferences of type $b$ will not tolerate further opportunities emerging from the shift in the frontier, whereas individuals with preferences of type $a$ will want to move from point $C$ to a combination lying within the $C D$ segment of the frontier. Preferences of type $b$, therefore, consider more morally charged solutions as repugnant. With the experiment described below, we hope to make progress in understanding what kind of preferences characterize individuals when faced with information on the effectiveness of ways to solve the organ shortage that are morally charged: Do they consider these ways repugnant regardless of their efficiency, or are they willing to support them if they promise to better solve a social problem like the shortage of organs? ${ }^{3}$

\footnotetext{
${ }^{3}$ Another possibility is that different individuals may have the same preferences but different perceptions of the frontier and how it changes when further information becomes available. In the experiment below, we controlled in part for this by asking subjects about their perceived reliability of the provided information. The analysis of heterogeneous treatment effects also provides some insights as to the relevance of this interpretation of our framework. In the concluding section we discuss further direction of research to test for these different interpretations.
} 


\subsection{Research design}

We recruited 2,393 subjects in May 2014, and 1,024 subjects in September 2014, via Amazon Mechanical Turk (mTurk), an Amazon Web Service platform that allows reaching a large number of individuals to perform tasks online and is increasingly used for surveys and experiments (Buhrmester and Kwang 2011; Mason and Suri 2012). Upon agreeing to participate in the study (described as a “computerized questionnaire") and to receive $\$ 0.75$ upon its completion (the tasks altogether took about 5 minutes, making the implied hourly wage slightly above the mTurk average for North America), the subjects were randomly assigned to one of the following conditions:

- Control: For subjects in this experimental condition, we first elicited their attitudes toward legalizing payments for organ donors or their families in case of deceased donation; then, we administered a survey with questions about their demographics and socio-economic characteristics. Details on the survey questions and structure can be found in the Appendix.

- Organs text: Individuals in this treatment condition were first informed that they would be shown a text, followed by a reading comprehension question. The text (reproduced in full in the Appendix) reported information about the current organ supply shortage in the United States, and described a number of proposals that have been advanced or, in some cases, implemented to reduce such shortage, with references to the academic studies advancing or evaluating these proposals. These included kidney exchange programs (Roth et al. 2004) as well as studies estimating the effects of introducing monetary compensation for donors (Becker and Elías 2007). After the text, a comprehension question was given to the subjects. In the first experimental wave, subjects in this group were randomly assigned one of four different questions; the objective of proposing different questions was to assess whether further focusing attention on different parts of the text, and in particular on the effects of a market-based solution to reduce the organ supply shortage, would affect differently the support for the market-based solution. We did not find meaningful differences in support rate based on the questions that the subjects received (see Appendix Table A3); for this reason, we proposed only one comprehension question to all subjects in the subsequent experimental wave. In the analyses presented here, we pooled all subjects who were given the organs text in the same treatment group, regardless of the specific comprehension questions that they received. The remainder of the survey was the same as that the one presented to the control group, with elicitation of attitudes toward payments for donors, and a socio-economic survey. 
- "Placebo" text: This condition had the same structure as the organ text treatment; however, instead of a text on organ supply shortage, an unrelated, morally neutral text concerning the causes of the flu and remedies for it, as well as a related comprehension question, was provided to the subjects. This treatment was implemented only in the May 2014 wave. The rationale for this condition was to test whether any changes in support for organ payments could be attributed to having read and reflected upon some topic-relevant information (as in the organ text condition described above) rather than to the subjects' attention being heightened by the simple fact of having been asked to carefully read a text, irrespective of its content.

We employed the "Item Count Technique" (ICT) to measure support rates for organ payments. The ICT is based on not asking a question directly (e.g., "Would you support the implementation of regulated payments for organ donors or their families?"); instead, respondents are shown a set of statements and are then asked to indicate how many apply to them. The control group is given a list of $\mathrm{N}$ "neutral” statements (i.e., non-sensitive in nature and not related to the research topic) whereas the treatment group is given $\mathrm{N}+1$ sentences, of which $\mathrm{N}$ is the same as for the control group, and the additional item is the one of interest for the researcher. Thus the researcher cannot infer whether a given respondent answered positively or negatively to a specific item; only the total number of items that apply to an individual is identifiable. This preserves the privacy of the respondents and, together with the anonymity of the online survey, allays the concern that the subjects might give what they perceive to be the "socially correct" answer. In our case, the hypothetical framework might lead to a downward bias if most respondents believed that paying for organs was generally considered morally wrong. The random assignment of subjects to the experimental conditions, the choice of statements that are not perfectly correlated (to avoid individuals agreeing with all or none of them, thus effectively revealing their opinion on each statement), and the use of a large enough sample size, make the difference in the average counts between treatment and control a valid estimate of the share of individuals in the population under study to which the phrase of interest applied (Coffman et al. 2013, Miller 1984). In our study, within each of the experimental conditions, subjects were further randomly divided in two subgroups of roughly equal size: one receiving four statements, and one receiving five statements. The fifth statement was a sentence indicating that the respondent would support the establishment of a regulated system of payments for organs and, overall, the statements were chosen such that the majority of respondents would be unlikely to agree with either all of them or none of them (see the Appendix for details). The distribution of responses (Table 1) confirms that we achieved this goal. The sample sizes for each treatment condition (at the level of the split between 
being assigned four and five statements) were chosen so that we would be able to detect, with $5 \%$ confidence and $80 \%$ power, differences of at least 10 percentage points in support rate. Smaller differences, even if precisely estimated, would be of relatively limited interest.

Most of our analyses were conducted after pooling together the control and placebo text subjects, because there was no difference in their responses (Table A3 in the Appendix reports estimates for the more disaggregated analyses). The model that we estimated is as follows:

$Y_{i}=\beta_{C 4}+\beta_{C 5} D_{i C 5}+\beta_{O 4} D_{i O 4}+\beta_{O 5} D_{i O 5}+\gamma X_{i}+\varepsilon_{i}$

where $Y_{i}$ is the count of statements with which subject $i$ is in agreement, and the binary indicators $D_{i C 5}, D_{i O 4}$ and $D_{i O 5}$ take a value of 1 if subject $i$ is assigned to the control (or placebo text) group with five statements, in the organ text group with four statements, and in the organ text group with five statements, respectively. Thus, the estimate $\hat{\beta}_{C 4}$ indicates the average number of statements for the control-group subjects who received four statements. The estimate $\hat{\beta}_{C 5}$ reports the difference between the number of agreed to statements by subjects in the control group who had five statements, and those who received four statements, or the percentage of subjects who would support the establishment of regulated payments for organs. Similarly, the difference $\hat{\beta}_{O 5}-\hat{\beta}_{O 4}$ is the estimate of the approval rate for payments to organ donors for those who received a text about the organ supply

shortage. Finally, $\left(\hat{\beta}_{O 5}-\hat{\beta}_{O 4}\right)-\hat{\beta}_{C 5}$ estimates the difference in approval rate between the control group and the treatment group, our main treatment effect of interest. The vector $X_{i}$ includes covariates derived from the survey responses, as well as an indicator for the wave in which the experiment was conducted. The experimental design is represented in Figure 2.

\section{Results}

\subsection{Main findings}

About $56 \%$ of the 3,417 respondents were men, and their average age was 31.6 years. The median subject was not married, had no children, had a monthly income between $\$ 1,500$ and $\$ 2,500$, volunteered or donated money to a charity in the previous two years, and had some college education. About 53\% were employees, $13.5 \%$ self-employed, and 15\% students. Approximately $52 \%$ reported being religious and $48.5 \%$ had liberal political views. Table A1 in the Appendix provides a full breakdown of these descriptive characteristics and shows that the sample was balanced between experimental conditions. 
The values reported in Figures 3-5 and the associated standard errors derive from estimating Equation 1 above without adding covariates other than the treatment indicators. As a baseline finding, $52.6 \%$ of subjects in the control group expressed a positive opinion toward establishing regulated payments for organ donors or their families. Although the mTurk sample used in this research was not fully representative of the American population (see Table A2 in the Appendix), the baseline approval rate that we obtained was similar to what found in previous studies based on representative samples of the US population (Leider and Roth 2011).

We focus on the difference in approval between the treatment group (i.e., the subjects who were exposed to the text on organ shortages and potential solutions) and the control group. Figure 3 shows that, for the treatment group, support for payment for organs increased to $72.8 \%$, or 20.2 percentage points over the baseline (s.e. $=6.3 \%$ ). Another way to read this result is that about $38.5 \%$ of those who would not initially support payments for organs changed their attitudes when given verifiable information and researched considerations about the organ shortage and potential ways to solve this problem. The estimates did not meaningfully change in regressions that included covariates for the socio-economic characteristics of the respondents and a wave dummy; the estimates when controls were added indicated a change in approval from $51.8 \%$ to $71.3 \%$, or a difference of 19.5 percentage points $(p<0.01)$, as shown in Table 2 .

The overall effect of information was not driven by any specific sub-group (Figure 4). Women and men had similar baseline levels of support and similar responses to information. Liberals and moderates were slightly more sensitive to information than were conservatives. Subjects with lower educational attainments had a larger response than those with at least a college degree, perhaps because they were less knowledgeable about the topic; conversely, this result may raise concern that less informed people may overreact to information. Similarly, subjects reporting a monthly personal income below $\$ 2,500$ (approximately the median level in the US) were marginally more reactive to information than those with higher earnings, and generally displayed less support for a market-based solution to alleviate organ supply shortages. Finally, people who reported being religious were less in favor of payments for organs and slightly less impacted by the information than were those who declared being atheist or agnostic. In general, as mentioned, all of these differences were small and of limited or no statistical significance. Appendix Table A4 reports the heterogeneous effects estimates from regressions that included the full set of controls. 


\subsection{Exploring mechanisms}

We conducted auxiliary analyses to explore possible sources of the results, and in particular to corroborate our interpretation that the changes in support for organ payments can be attributed to the subjects having read and reflected upon the topic-relevant information we provided.

First, pre-existing beliefs about payments for organs may have affected whether the subjects found the provided information credible or not, and this could in turn have had an effect on how people responded to information (Kahan et al. 2011). To explore this possibility, we asked the participants in the treatment group whether they found the information supplied in the text reliable (we did so after gauging their attitudes toward organ payments in order to not influence their response). Table 3 shows that about $90 \%$ of subjects responded that they found the provided information reliable; the perceived reliability of the placebo text about the flu was slightly higher. Because the overwhelming majority of the subjects considered the text reliable, differences in beliefs about the reliability of the information provided are not playing a role in our setting.

Second, we replicated the study (in September and October 2014, with a total of 2,762 new subjects) using two other activities prohibited by law in large part because considered ethically repugnant. The first issue was the legalization of indoor prostitution. In this case, the subjects were provided a text including information about recent academic work that showed that the legalization of indoor prostitution in a US state led to large reductions in sexual violence and certain sexually transmitted diseases (Cunningham and Shah 2014). We expected the case of prostitution to be ethically charged to a comparable extent as payments for organs, with the subject population being almost equally split between those in favor to it and those opposed. It is also reasonable to expect heterogeneities in the population in the reaction to information for this activity. For example, there is evidence that women and religious individuals are more opposed to legalizing prostitution (Brehman 2010, Jakobsson and Kotsadam 2009, May 2009). These different views may also affect how information is interpreted. Evidence of greater heterogeneities as compared to the case of organ payments would offer further support to the interpretation that the effects that we found derive from actual reflection and specific reactions to the information supplied. The second topic that we chose was a case for which we expected both very low approval rates and minimal impact of information and cost-benefit considerations: the legalization of slavery contracts. In this case, subjects were assigned a text that reported historical evidence about the relative condition of slaves and freed men in the US before and after the abolition of slavery (Fogel and Engerman 1974), information about the current presence of millions of de facto slaves in developing countries, and that suggested that 
allowing slavery contracts might improve the living conditions of de facto slaves. Results from comparing mean levels of support are reported in Figure 5, and a complete set of estimates from all of these analyses can be found in Appendix Table A5. ${ }^{4}$

A few patterns emerged from these data. First, the overall level of support for legalizing indoor prostitution exceeded $60 \%$, a little higher than payments for organs; by contrast, it was very low (about 5\% and statistically indistinguishable from zero) for the legalization of slavery. Second, in both cases, there was no sizeable or statistically significant effect of the text on the support for legalizing the activity. Third, the overall absence of a response to information masked considerable heterogeneity across different sub-groups of subjects. For example, women and men had different reactions to the information about the beneficial effects of legalizing indoor prostitution; the information produced increased support among men, but decreased support among women. The decrease for women may be due to this subgroup reacting to the additional focus on prostitution with even more repugnance; alternatively, this may be due to women expecting even larger gains in efficiency from legalization of the activity. Similarly, a relatively large proportion of men supported the introduction of a regulated framework for slavery contracts as a result of being exposed to the arguments presented in the text whereas the effect on women was small and in the opposite direction. These responses were in contrast to those produced by the case of organ payments, for which the effects were very similar between genders. Support rates as well as size and direction of responses to information also differed based on whether subjects were religious in the case of legalizing prostitution (religious subjects had lower support rates and minimal reaction to information), and on political views in the case of legalizing slavery (although estimates were very imprecise and generally not significantly different from zero; the few negative estimates should be attributed the limited size of some of the sub-samples that created additional noise).$^{5}$

These findings reinforce our interpretation that the effects that we found in the case of organ payments were not an automatic reflex of experimental subjects to any kind of information presented to them; in other words, subjects were paying close attention to the actual content of the texts and responded to the information provided. ${ }^{6}$ The results are also consistent with the presence of limited

\footnotetext{
${ }^{4}$ The Appendix also includes a graphical representation of these additional interventions (Figures A1 and A2) as well as the texts and questions on legalizing prostitution and slavery that were administered to the subjects

${ }^{5}$ The differences in responses along other individual characteristics-such as income and education for both prostitution and slavery, religiosity for slavery, and political views for prostitution - were limited in size and statistical significance (we report these in the Appendix).

${ }^{6}$ An additional result from a companion paper (Elias, Lacetera and Macis 2015) provides further corroboration for our interpretation of the findings here. We tested the effect of a generic text describing the beneficial welfare properties of market exchanges. The text treatment had a statistically insignificant (directionally negative) effect on
} 
heterogeneity in individuals' preferences in the case of organ payments. For the case of prostitution and slavery, the fact that there are some specific groups that are not sensitive to the information provided implies, in contrast, that preferences heterogeneity is more relevant, and as a consequence repugnance is more likely to persists.

\section{Discussion}

Whether an activity is perceived as morally acceptable is resolved by every society with variations depending on time, location, and cultural norms; these choices are part of the social contract that ties a community together. Because prohibiting an activity on the ground of its moral repugnance does not necessarily have an objective, rational basis, differences are to be expected. Although these attitudes may be very deeply held, investigations into whether logical arguments or empirical evidence about the effects of allowing a given repugnant transaction affect these attitudes is valuable; these studies may offer insights into whether it is possible to change the position of a portion or even the majority of a population. This is particularly relevant when repugnance-based prohibitions limit the possibility to implement life-saving solutions to such problems as the shortage of human organs for transplantation, or to even empirically evaluate these solutions, for example in pilot trials. ${ }^{7}$

In this study we found that, when provided with information about and arguments for different strategies to address the organ shortage, including the potential benefits of payments to organ donors, the share of individuals showing support for a market-based solution increased substantially. Supplementary evidence regarding support for two other repugnant activities (slavery and prostitution) showed that the role of information and cost-benefit considerations in changing attitudes was heterogeneous and specific to each topic, and also interacted with deeply held beliefs and other individual characteristics such as gender, religiosity, and political orientation. Thus, at any given time, not all beliefs about which transactions are repugnant are equally strong and immutable, or permeable to information. One further implication of these case-specific effects is that thinking about market solutions does not necessarily "corrupt" moral values (Falk and Szech 2013, Sandel 2012) by affecting people's preferences; if this were the case, we would likely see similar responses across the board. Instead (although we cannot provide direct evidence of this), thinking about tools to achieve

attitudes about organ payments and legalized prostitution, again suggesting that attitudes about payments to organ donors were due to the information provided about costs and benefits specific to this transaction.

7 See for example the correspondence between Delmonico et al. (2012) and Matas et al. (2012) on whether these trials should be implemented. 
more effective solutions (e.g., to the organ shortage problem) might shift the attention from the moral judgement of a third party to the interests of the parties involved in the transaction.

Our findings provide insights into the role of information and scientific evidence in how people perceive activities and transactions that are morally charged and the importance of the choice set in individuals decisions; supplying evidence and promoting studies on a number of sensitive topics might therefore lead to greater awareness and improved policy design based on the actual preferences of a population. In the case of introducing regulated payments for organ donors and their families in particular, the evidence is particularly strong that informing society about the potential benefits of economic incentives does impact the acceptability of this transaction. However, the heterogeneity within and between activities described above points to the complexity of such interventions, and is consistent with taking a case-specific approach to these issues.

The results also relate to a number of related studies in several disciplines, such as research on how beliefs affect individual analytical reasoning (Kahan 2003, Leget 2009), whether ethical principles are, at least in part, evidence-based (Heath 2012), and whether ethical decisions and actions depend on information about the costs and benefits of these choices (Gibson et al. 2013). The findings, finally, are consistent with attitudes toward repugnant markets evolving over time in response to changes in the costs and benefits of the underlying activities, for example due to technological progress (Elías 2015).

Further research to investigate the trade-offs that individuals face between rational (or evidencebased) arguments and deeply-held moral beliefs appears promising for both scholarly advancements and shaping public policy. 


\section{References}

Alesina, A. and Giuliano, P., forthcoming: "Culture and Institutions," Journal of Economic Literature.

American Society of Transplantation (AST), 2014: "The Cost of Giving," http://www.myast.org/blog/the-cost-ofgiving.

Anteby, M., 2010: "Markets, morals, and practices of trade: Jurisdictional disputes in the U.S. commerce in cadavers," Administrative Science Quarterly, 55, 4, 606-38.

Baron, J. and Leshner, S., 2000: "How serious are expressions of protected values?," Journal of Experimental Psychology: Applied, 6, 3, 183-194.

Baron, J., and Spranca, M., 1997: "Protected values," Organizational Behavior and Human Decision Processes, 70, $1-16$.

Beard, David L. Kaserman, and Rigmar Osterkamp, 2013: The Global Organ Shortage Economic Causes, Human Consequences, Policy Responses, Stanford University Press.

Bisin, A. and Verdier, T., 2010: "The Economics of Cultural Transmission and Socialization," in Handbook of Social Economics, Jess Benhabib, Alberto Bisin, Matt Jackson, eds., Elsevier.

Brehman, B.R., 2010: "Factors Influencing Attitudes towards Prostitution," University of Nevada working paper.

Buhrmester, M., Kwang, T. and Gosling, S.D., 2011: “Amazon's Mechanical Turk: A new source of inexpensive, yet high-quality, data?," Perspectives on Psychological Science, 6, 3-5.

Becker, G.S. and Elías, J.J., 2007: "Introducing incentives in the market for live and cadaveric organ donations," Journal of Economic Perspectives, 21, 3, 3-24.

Becker, G.S. and Elías, J.J., 2014: "Cash for Kidneys: The Case for a Market for Organs," The Wall Street Journal, 01/18/2014 (http://online.wsj.com/articles/SB10001424052702304149404579322560004817176).

Coffman, K., Coffman, L., and Ericson, K., 2013: "The size of the LGBT population and the magnitude of Anti-Gay sentiment are substantially underestimated," NBER working paper 19508.

Cunningham, S. and Shah, M., 2014: "Decriminalizing indoor prostitution: Implications for sexual violence and public health," NBER working paper 20281.

Delmonico, F.L. et al., 2002: "Ethical Incentives - Not Payment - for Organ Donation," N Engl. J Med, 346, 25, 2002-05.

Delmonico F, Danovitch, G., Capron, A., Levin, A. and Chapman, J., 2012: "Proposed Standards for Incentives for Organs Donation Are Neither International Nor Acceptable," American Journal of Transplantation, 12, 195455.

Elías, J.J., 2015: "The role of repugnance in the development of markets: The case of the market for kidneys for transplants," forthcoming in Costa-Font, J. and Macis, M. (Eds.), Social Economics, Cambridge: MIT Press.

Elías, J.J., Lacetera, N. and Macis, M., 2015: "Markets and Morals: An Experimental Survey Study,” working paper.

Falk, A. and N. Szech (2013), "Morals and Markets," Science 340, 707-711.

Fogel, R.W. and Engerman, S.L., 1974: Time on the Cross. The Economics of American Negro Slavery, Boston: Little, Brown and Company.

Gaston, R.S. et al., 2006: "Limiting Financial Disincentives in Live Organ Donation: A Rational Solution to the Kidney Shortage," American Journal of Transplantation, 6, 11, 2548-55.

Gibson Brandon, R., Tanner, C. and Wagner, A.F., 2013: "Preferences for Truthfulness: Heterogeneity Among and Within Individuals," American Economic Review, 103, 1, 1-18.

Guiso, L., Sapienza, P. and Zingales, L., 2006: "Does Culture Affect Economic Outcomes?," Journal of Economic Perspectives, 20, 2, 23-48.

Heath, J., 2012: "Letting the World In: Empirical Approaches to Ethics," The Ethics Forum, 7, 3, 93-107.

Jakobsson, N. and Kotsadam, A., 2009: "What Explains Attitudes Toward Prostitution?," University of Göteborg working paper.

Kahan, D.M., 2003: "Ideology, Motivated Reasoning, and Cognitive Reflection," Judgment and Decision Making, $8,407-24$. 
Kahan, D.M., Jenkins-Smith, H. and Braman, D., 2011: “Cultural Cognition of Scientific Consensus,” Journal of Risk Research, 14, 147-74.

Lacetera, N., Macis, M. and Slonim, R., 2013: "Economic Rewards to Motivate Blood Donations," Science, 340, 6135, 927-28.

Leget, C. et al., 2009: "Nobody tosses a Dwarf: The Relation between the Empirical and the Normative Reexamined," Bioethics, 23, 4, 226-235.

Leider, S. and Roth, A.E., 2010: "Kidneys for sale: Who disapproves, and why?," American Journal of Transplantation, 10, 1221-27.

Matas, Arthur J. and Schnitzler, M., 2003: "Payment for Living Donor (Vendor) Kidneys: A Cost-Effectiveness Analysis," American Journal of Transplantation, 4, 216-21.

Maio, G.R., and Olson, J.M., 1998: "Values as truisms: Evidence and implications," Journal of Personality and Social Psychology, 74, 294-311.

Mason, W. Suri, S., 2012: “Conducting Behavioral Research on Amazon's Mechanical Turk,” Behavioral Research Methods, 44, 1, 1-13.

Matas, A. et al., 2012: "A Realistic Proposal-Incentives May Increase Donation-We Need Trials Now!," American Journal of Transplantation, 12, 1957-58.

May, D.C., 1999: "Tolerance of Nonconformity and Its Effect on Attitudes toward the Legalization of Prostitution: A Multivariate Analysis," Deviant Behavior: An Interdisciplinary Journal, 20, 335-58.

Miller, J.D., 1984: A New Survey Technique for Studying Deviant Behavior, Ph.D. dissertation, George Washington University.

Molevich, B. et al., 2004: "Empirical Data and Moral Theory. A Plea for Integrated Empirical Ethics," Medicine, Health Care and Philosophy, 7, 55-69.

Nyhan, B. and Reifler, J., 2014: "Does Correcting Myths about the Flu Vaccine Work? An Experimental Evaluation of the Effects of Corrective Information," Vaccine, 3, 9, 459-64.

Nyhan, B., Reifler, J., Richey, S. and Freed, G.L., 2014: "Effective Messages in Vaccine Promotion: A Randomized Trial," Pediatrics. 133, 4, 835-42.

Roth, A.E., 2007: "Repugnance as a Constraint on Markets," Journal of Economic Perspectives, 21, 3 , $37-58$.

Roth, A.E., 2014: "In 100 years” in Ignacio Palacios-Huerta (ed.), In 100 Years, MIT Press.

Roth, A.E., Sonmez, T. and Unver, M.U., 2004: “Kidney exchange,” Quarterly Journal of Economics, 119, 2, 45788.

Sandel, M., 2012: What Money Can't Buy: The Moral Limits of Markets, Farrar, Straus and Giroux.

Seligman, C. and Katz, A. N., 1996: “The dynamics of value systems," In C. Seligman, J.Olson and M. Zanna (eds.), Values: The Ontario Symposium, 8 53-75, Hillsdale, N.J.: Erlbaum.

Strech, D., 2008: "Evidence-Based Ethics -- What it Should Be and What It Shouldn't," BMC Medical Ethics, 9, 16.

The New York Times, 2014: How Much for a Kidney? (http://www.nytimes.com/roomfordebate/2014/08/21/howmuch-for-a-kidney).

United Network for Organ Sharing (UNOS). http://www.unos.org/donation/index.php?topic=data. Accessed 10/1/2014.

Zelizer, V., 1979: Morals and Markets: The Development of Life Insurance in the United States, New York: Columbia University Press, 1979. 


\section{Figures and tables}

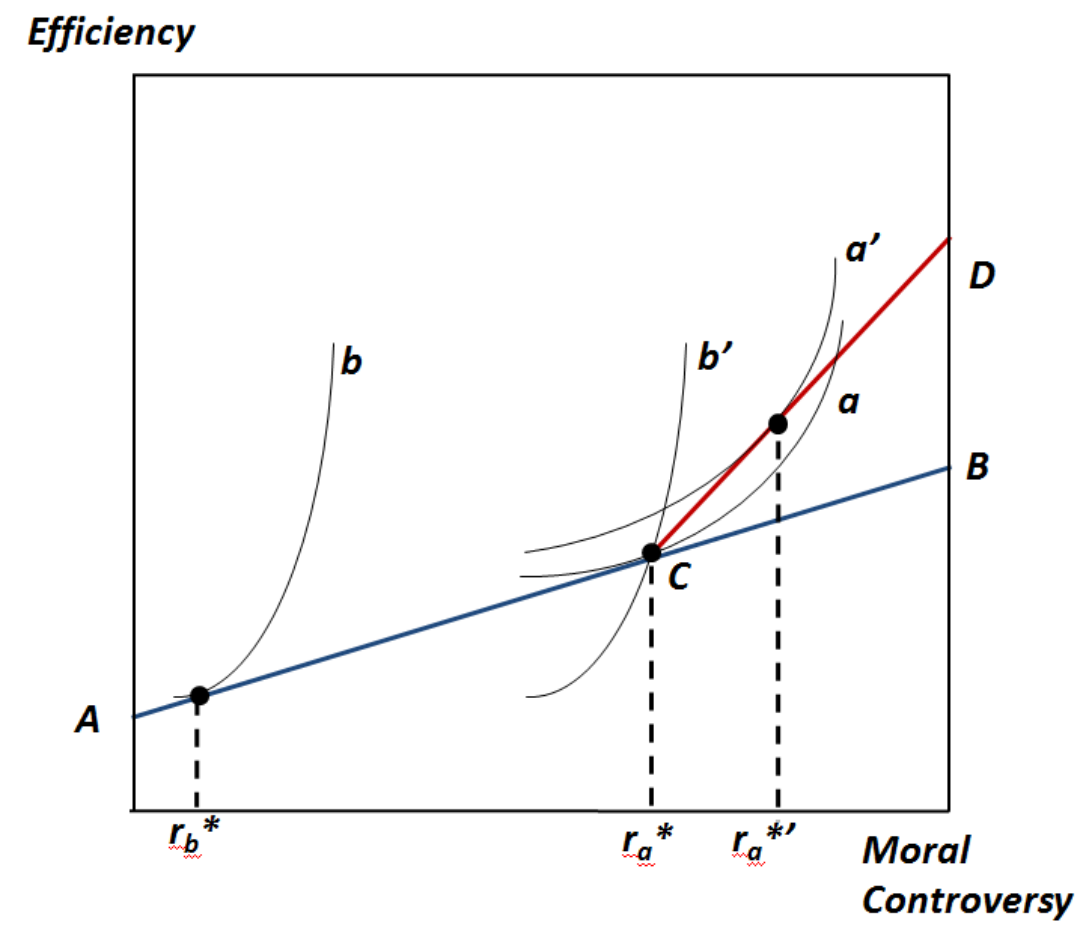

Figure 1: The efficiency - moral controversy trade off under different possibility frontiers and preferences. 
3417 subjects invited to take a "computerized questionnaire" on mTurk, May and September 2014

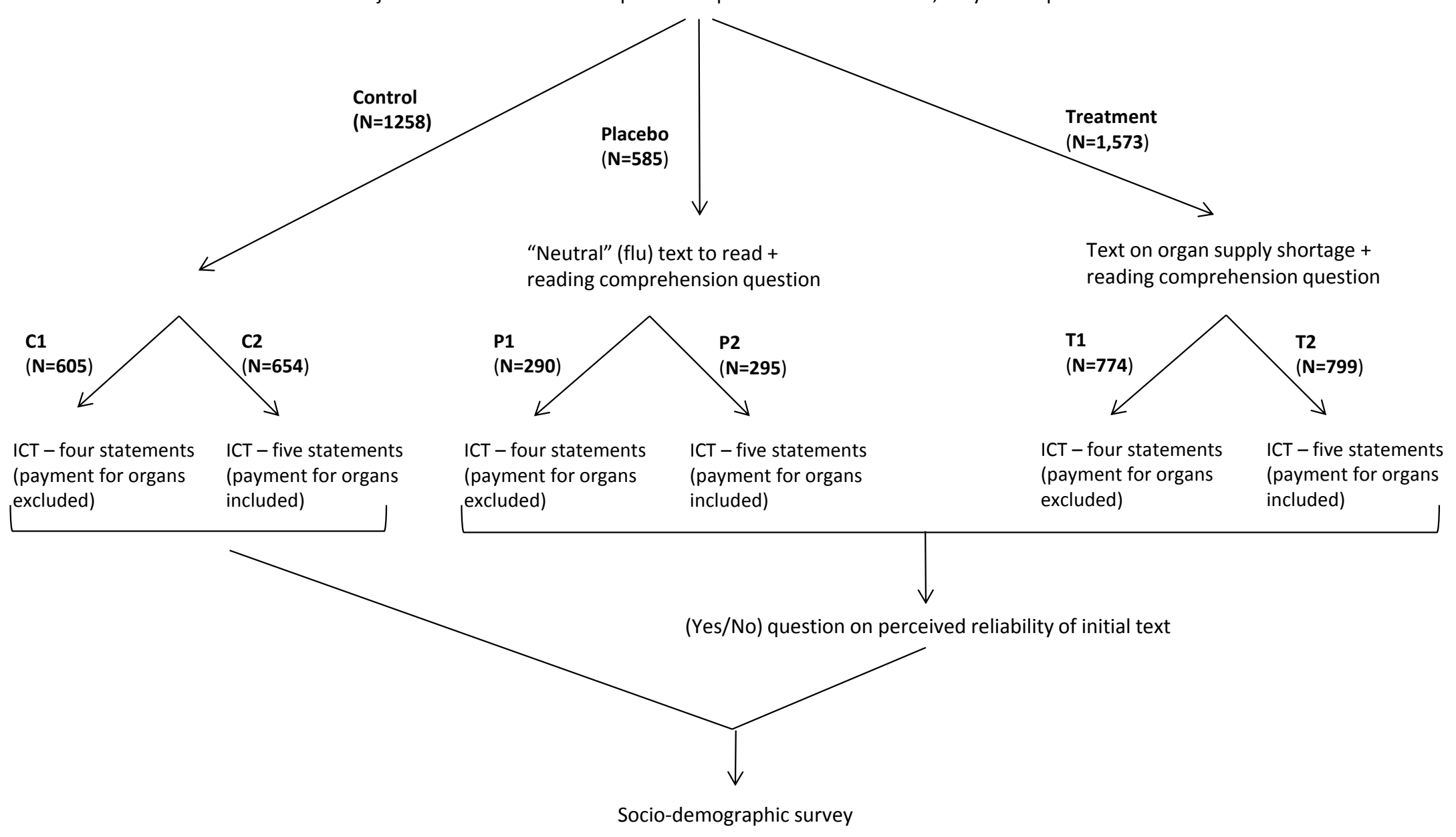

Figure 2: Experimental design 


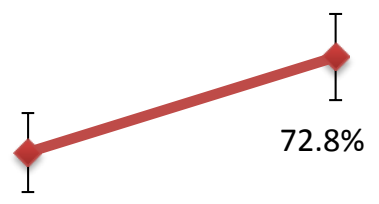

$52.6 \%$

No text/placebo text Organs text

Figure 3: Estimated percentage of subjects favoring payments for organs, by treatment. The values were calculated as the differences between the average number of statements with which the subjects were in agreement when provided with five statements (including the statement about support for payment for organs) and the average number of statements with which the subjects were in agreement when provided with four statements (excluding the statement about support for payment for organs). The "No text" subsample includes the subjects who were provided with the "placebo" text. The vertical bars indicate $95 \%$ confidence intervals for the estimates. 


\section{Support for payments for organs, by gender}

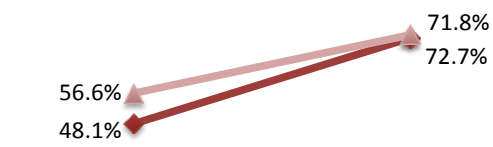

$$
\begin{aligned}
& - \text { women } \\
& - \text { men }
\end{aligned}
$$

No text/placebo text

Organs text

Support for payments for organs, by educational attainment
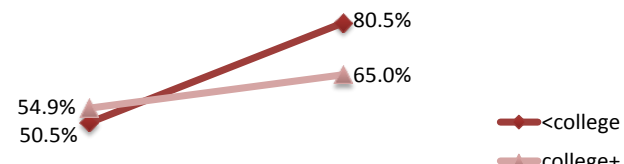

- college+

No text/placebo text

Organs text

Support for payments for organs, by political views

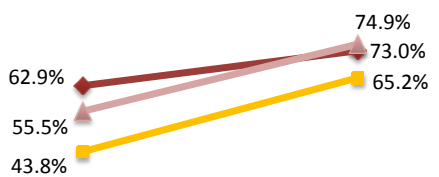

No text/placebo text

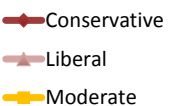

-Moderate
Support for payments for organs, by religiosity

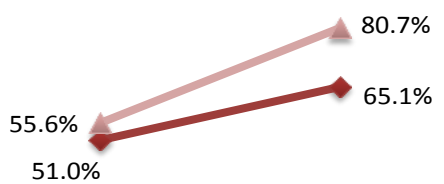

Religious

- Non religious
Support for payments for organs, by monthly income

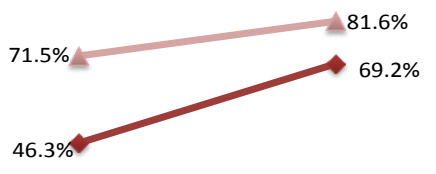

$\longrightarrow>=\$ 2500$

$\leadsto \$ 2500$

Figure 4: Estimated percentages of subjects favoring payments for organs, by experimental condition and individual characteristics. 


\section{Support for legalizing indoor prostitution}

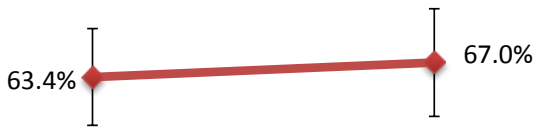

Support for legalizing indoor prostitution, by gender
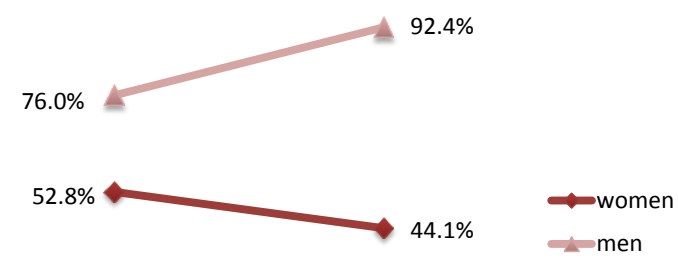

No text

Prostitution text
Prostitution text

Support for legalizing indoor prostitution, by religiosity

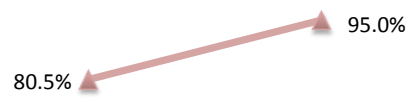

$51.5 \%$

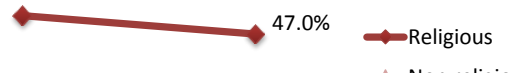

$\leadsto$ Non religious

\section{Support for legalizing slavery}

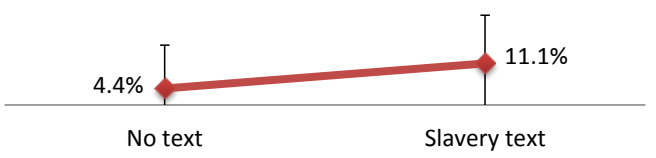

Support for legalizing slavery, by gender

Support for legalizing slavery, by political views
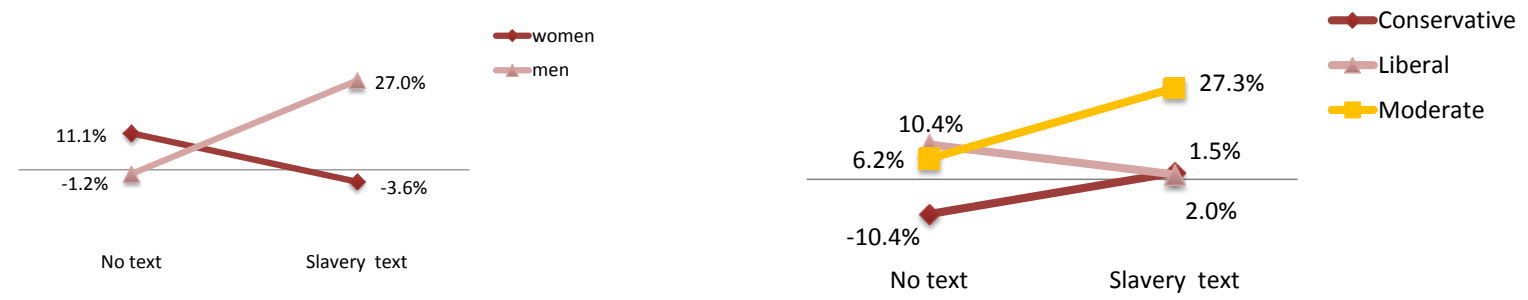

Figure 5: Estimated percentage of subjects favoring legalized indoor prostitution and slavery, overall and for selected individual characteristics. 


\begin{tabular}{cccc}
\hline \hline $\begin{array}{c}\text { Number of statements } \\
\text { that apply to subject }\end{array}$ & $\begin{array}{c}\text { 4 statements } \\
\text { received (N=1669) }\end{array}$ & $\begin{array}{c}5 \text { statements } \\
\text { received ( }=1748)\end{array}$ & Total \\
\hline 0 & $2.9 \%$ & $2.4 \%$ & $2.6 \%$ \\
1 & $22.5 \%$ & $10.6 \%$ & $16.4 \%$ \\
2 & $50.6 \%$ & $31.6 \%$ & $40.9 \%$ \\
3 & $21.6 \%$ & $37.8 \%$ & $29.9 \%$ \\
4 & $2.5 \%$ & $15.4 \%$ & $9.1 \%$ \\
5 & & $2.3 \%$ & $1.2 \%$ \\
\hline \hline
\end{tabular}

Table 1: Distribution of number of statements with which subjects reported to agree.

\begin{tabular}{lcc}
\hline \hline & $(1)$ & $(2)$ \\
& \multicolumn{1}{c}{ Outcome variable: } & Statements that apply to subject \\
\hline Constant & $1.982^{* * *}$ & $1.354^{* * *}$ \\
& $(0.027)$ & $(0.510)$ \\
Control (no text/placebo text, 5 & $0.526^{* * *}$ & $0.518^{* * *}$ \\
statements & $(0.043)$ & $(0.042)$ \\
Organ text, 4 statements & 0.00237 & -0.000788 \\
& $(0.040)$ & $(0.040)$ \\
Organs text, 5 statements & $0.730^{* * *}$ & $0.713^{* * *}$ \\
& $(0.045)$ & $(0.045)$ \\
Covariates & No & Yes \\
Organs text: 5 statements - 4 & $0.727^{* * *}$ & $0.713^{* * *}$ \\
statements (share in favor of & $(0.046)$ & $(0.047)$ \\
organ payment in organ text & & \\
condition) & & $0.195^{* * *}$ \\
& & $(0.063)$ \\
5 statements - 4 statements: & $0.202^{* * *}$ & \\
Organs text - control (difference & $(0.063)$ & 3,413 \\
in share in favor of organ & & \\
payments between organ text & & \\
and control conditions) & & \\
R-squared & & \\
Obs. & & \\
\hline \hline
\end{tabular}

Table 2: Ordinary Least Squares Regression estimates. Covariates include indicators for levels of gender, job status, income level, educational attainment, relationship status, whether the respondent has children, monthly income, political views, religious beliefs, whether the subject donated to charity or volunteered in the previous two years, state of residence, as well as age in linear and quadratic value. An indicator for the second intervention wave is also added. The specific categories and the distribution in the population are reported in table S1 of the Appendix. Huber-White robust standard errors in parentheses. ${ }^{* *} \mathrm{p}<0.05 ;{ }^{* * *} \mathrm{P}<0.01$. 


\begin{tabular}{lc}
\hline \hline Treatment condition & $\begin{array}{c}\text { Share of subjects finding the } \\
\text { information in the text reliable }\end{array}$ \\
\hline Placebo text, 4 statements & $93.4 \%$ \\
Placebo text, 5 statements & $94.6 \%$ \\
Organ text, 4 statements & $89.8 \%$ \\
Organ text, 5 statements & $89.1 \%$ \\
\hline \hline
\end{tabular}

Table 3: perceived reliability of the provided text 
APPENDIX 


\section{Additional figures and tables}

1590 subjects invited to take a "computerized questionnaire" on mTurk, September and October 2014

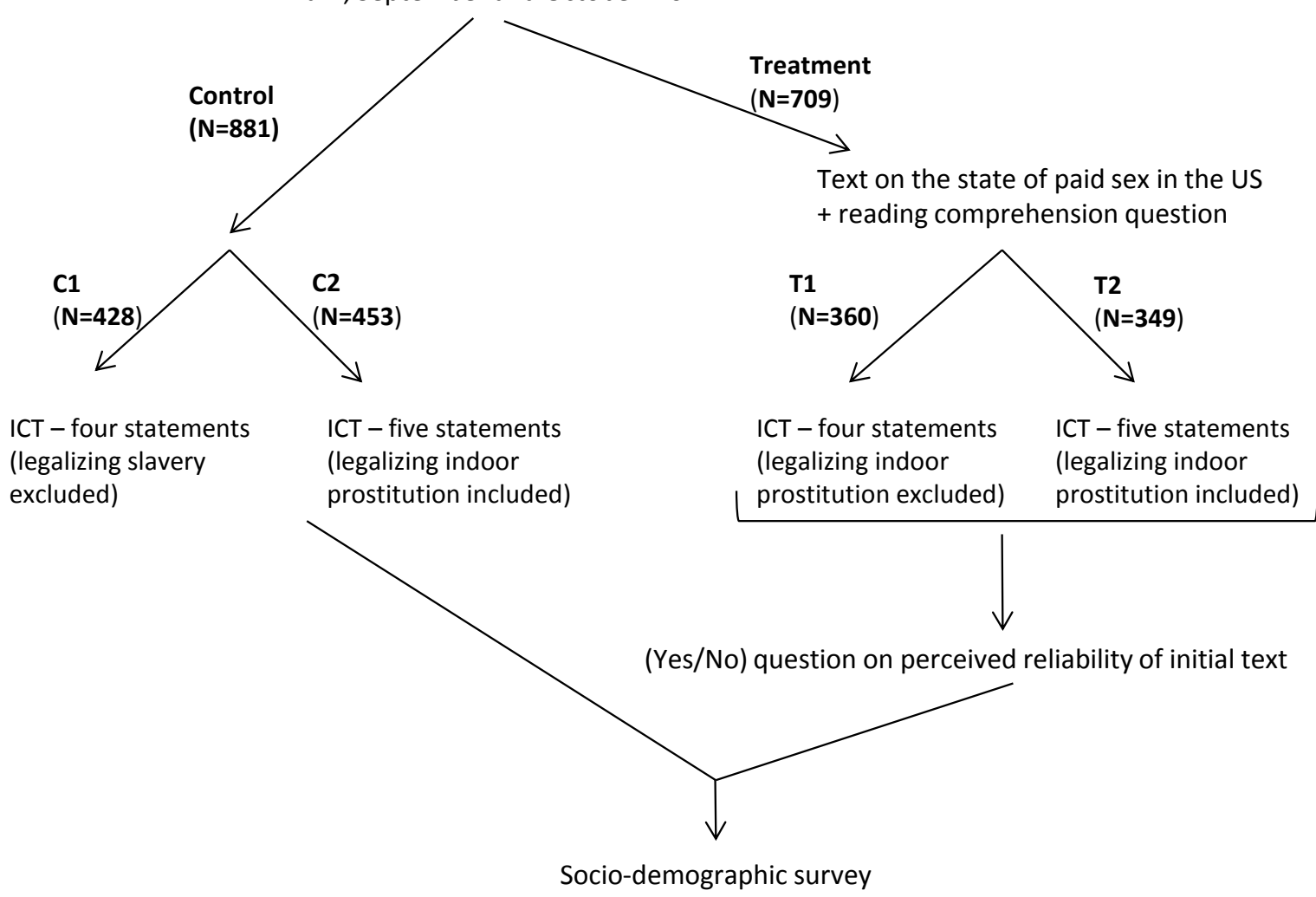

Figure A1: Experimental design - attitudes toward legalizing indoor prostitution. 


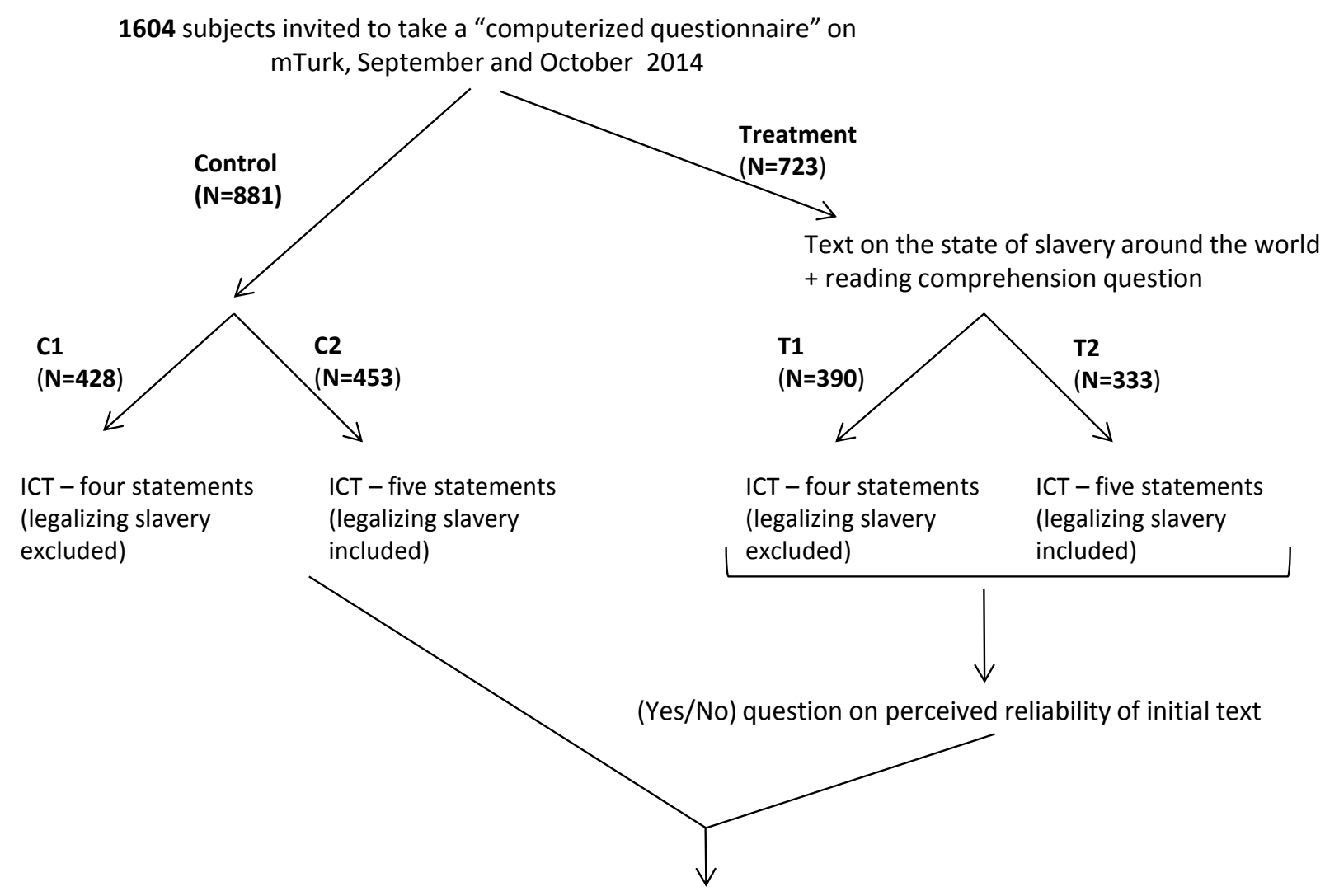

Socio-demographic survey

Figure A2: Experimental design - attitudes toward legalizing slavery contracts. 


\begin{tabular}{|c|c|c|c|c|c|}
\hline & $\begin{array}{l}\text { No text/placebo } \\
\text { text, } 4 \text { statements }\end{array}$ & $\begin{array}{l}\text { No text/placebo } \\
\text { text, } 5 \text { statements }\end{array}$ & $\begin{array}{l}\text { Organ text, } 4 \\
\text { statements }\end{array}$ & $\begin{array}{l}\text { Organ text, } 5 \\
\text { statements }\end{array}$ & Total \\
\hline & \multicolumn{5}{|c|}{ Average age } \\
\hline & 31.6 & 31.9 & 31.3 & 31.3 & 31.6 \\
\hline & \multicolumn{5}{|c|}{ Gender } \\
\hline Women & $42.8 \%$ & $45.4 \%$ & $45.1 \%$ & $40.7 \%$ & $43.6 \%$ \\
\hline \multirow[t]{2}{*}{ Men } & $57.2 \%$ & $54.6 \%$ & $54.9 \%$ & $59.3 \%$ & $56.5 \%$ \\
\hline & \multicolumn{5}{|c|}{ Ethnicity } \\
\hline White/Caucasian & $76.9 \%$ & $76.8 \%$ & $78.8 \%$ & $77.6 \%$ & $77.5 \%$ \\
\hline African American & $7.8 \%$ & $7.6 \%$ & $5.8 \%$ & $6.4 \%$ & $7.0 \%$ \\
\hline Hispanic & $6.0 \%$ & $5.6 \%$ & $5.6 \%$ & $5.6 \%$ & $5.7 \%$ \\
\hline Asian & $7.5 \%$ & $8.0 \%$ & $8.3 \%$ & $8.8 \%$ & $8.1 \%$ \\
\hline \multirow[t]{2}{*}{ Other } & $1.8 \%$ & $2.0 \%$ & $1.6 \%$ & $1.6 \%$ & $1.8 \%$ \\
\hline & \multicolumn{5}{|c|}{ Educational attainment } \\
\hline Primary School & $0.0 \%$ & $0.0 \%$ & $0.5 \%$ & $0.4 \%$ & $0.2 \%$ \\
\hline Some high school & $1.7 \%$ & $1.6 \%$ & $0.7 \%$ & $1.8 \%$ & $1.4 \%$ \\
\hline High School & $12.5 \%$ & $11.7 \%$ & $11.8 \%$ & $12.8 \%$ & $12.2 \%$ \\
\hline Some university & $36.4 \%$ & $39.3 \%$ & $36.3 \%$ & $37.8 \%$ & $37.5 \%$ \\
\hline $\begin{array}{l}\text { Undergraduare university } \\
\text { degree }\end{array}$ & $38.9 \%$ & $36.5 \%$ & $38.9 \%$ & $35.5 \%$ & $37.4 \%$ \\
\hline \multirow{2}{*}{ Postgraduate } & $10.5 \%$ & $11.0 \%$ & $11.9 \%$ & $11.8 \%$ & $11.2 \%$ \\
\hline & \multicolumn{5}{|c|}{ Job status } \\
\hline Private employee & $35.9 \%$ & $35.0 \%$ & $36.6 \%$ & $38.1 \%$ & $36.3 \%$ \\
\hline Public employee & $18.3 \%$ & $18.1 \%$ & $14.3 \%$ & $17.0 \%$ & $17.1 \%$ \\
\hline $\begin{array}{l}\text { Self employed/ } \\
\text { entrepreneur }\end{array}$ & $12.2 \%$ & $12.9 \%$ & $15.1 \%$ & $14.1 \%$ & $13.5 \%$ \\
\hline Unemployed & $12.0 \%$ & $12.3 \%$ & $12.4 \%$ & $10.8 \%$ & $11.9 \%$ \\
\hline Housekeeper & $4.3 \%$ & $4.4 \%$ & $3.6 \%$ & $5.8 \%$ & $4.5 \%$ \\
\hline Student & $15.9 \%$ & $14.9 \%$ & $16.0 \%$ & $13.4 \%$ & $15.0 \%$ \\
\hline \multirow[t]{2}{*}{ Retired } & $1.6 \%$ & $2.4 \%$ & $1.9 \%$ & $0.9 \%$ & $1.7 \%$ \\
\hline & \multicolumn{5}{|c|}{ Monthly income } \\
\hline No income & $11.5 \%$ & $12.9 \%$ & $13.1 \%$ & $11.0 \%$ & $12.1 \%$ \\
\hline Less than $\$ 1,500$ & $37.2 \%$ & $35.5 \%$ & $36.6 \%$ & $33.8 \%$ & $35.8 \%$ \\
\hline Between $\$ 1,500$ and $\$ 2,500$ & $24.9 \%$ & $26.5 \%$ & $26.2 \%$ & $26.4 \%$ & $26.0 \%$ \\
\hline Between $\$ 2,500$ and $\$ 5,000$ & $19.8 \%$ & $18.3 \%$ & $18.2 \%$ & $21.9 \%$ & $19.5 \%$ \\
\hline \multirow[t]{2}{*}{ More than $\$ 5,001$} & $6.6 \%$ & $6.9 \%$ & $5.9 \%$ & $6.9 \%$ & $6.6 \%$ \\
\hline & \multicolumn{5}{|c|}{ Relatonship status } \\
\hline Single & $41.6 \%$ & $38.2 \%$ & $45.4 \%$ & $39.7 \%$ & $41.0 \%$ \\
\hline Unmarried in a relationship & $23.5 \%$ & $23.1 \%$ & $24.4 \%$ & $20.5 \%$ & $22.9 \%$ \\
\hline Married & $29.5 \%$ & $32.4 \%$ & $25.1 \%$ & $33.7 \%$ & $30.3 \%$ \\
\hline Separated/divorced & $5.0 \%$ & $5.9 \%$ & $5.0 \%$ & $5.3 \%$ & $5.3 \%$ \\
\hline \multirow[t]{2}{*}{ Other } & $0.5 \%$ & $0.5 \%$ & $0.1 \%$ & $0.9 \%$ & $0.5 \%$ \\
\hline & \multicolumn{5}{|c|}{ Children } \\
\hline Does not have children & $67.9 \%$ & $64.8 \%$ & $70.3 \%$ & $64.0 \%$ & $66.7 \%$ \\
\hline \multirow[t]{2}{*}{ Has children } & $32.1 \%$ & $35.2 \%$ & $29.7 \%$ & $36.1 \%$ & $33.3 \%$ \\
\hline & \multicolumn{5}{|c|}{ Political views } \\
\hline Conservative & $16.4 \%$ & $17.8 \%$ & $15.6 \%$ & $17.7 \%$ & $16.9 \%$ \\
\hline Liberal & $49.4 \%$ & $46.9 \%$ & $50.5 \%$ & $47.6 \%$ & $48.5 \%$ \\
\hline Moderate & $31.0 \%$ & $30.7 \%$ & $28.9 \%$ & $30.0 \%$ & $30.2 \%$ \\
\hline \multirow[t]{2}{*}{ Other } & $3.2 \%$ & $4.6 \%$ & $4.9 \%$ & $4.8 \%$ & $4.4 \%$ \\
\hline & \multicolumn{5}{|c|}{ Religious beliefs } \\
\hline Atheist/agnostic & $48.6 \%$ & $44.6 \%$ & $48.1 \%$ & $48.8 \%$ & $47.4 \%$ \\
\hline Christian & $41.4 \%$ & $43.6 \%$ & $41.7 \%$ & $41.1 \%$ & $42.0 \%$ \\
\hline Jewish & $2.4 \%$ & $1.7 \%$ & $2.6 \%$ & $1.4 \%$ & $2.0 \%$ \\
\hline Muslim & $6.9 \%$ & $9.3 \%$ & $6.9 \%$ & $7.9 \%$ & $7.8 \%$ \\
\hline Other & $0.8 \%$ & $0.8 \%$ & $0.8 \%$ & $0.9 \%$ & $0.8 \%$ \\
\hline & & Charitable/vo & unteering beha & ior & \\
\hline $\begin{array}{l}\text { Donated /volunteered in } \\
\text { past } 2 \text { years }\end{array}$ & $65.4 \%$ & $63.3 \%$ & $66.5 \%$ & $65.1 \%$ & $65.0 \%$ \\
\hline $\begin{array}{l}\text { Did not Donate /volunteer in } \\
\text { past } 2 \text { years }\end{array}$ & $34.6 \%$ & $36.7 \%$ & $33.5 \%$ & $34.9 \%$ & $35.0 \%$ \\
\hline
\end{tabular}

Table A1: Descriptive statistics on individual characteristics collected from the survey, overall and by experimental condition. 


\begin{tabular}{lccc}
\hline & $\begin{array}{c}\text { mTurk } \\
\text { sample }\end{array}$ & & US population \\
\cline { 2 - 2 } Age & 31.5 & & 44.3 \\
\% Female & $43.5 \%$ & & $52.4 \%$ \\
\% Caucasian & $77.5 \%$ & & $68.2 \%$ \\
\% Black & $7.0 \%$ & & $11.6 \%$ \\
\% Other ethnicity & $15.6 \%$ & & $20.2 \%$ \\
\% Married & $30.3 \%$ & & $54.1 \%$ \\
\% College degree & $48.7 \%$ & & $33.0 \%$ \\
\% Christian faith & $42.0 \%$ & & $76 \%$ \\
\% Conservative & $17.7 \%$ & & $39 \%$ \\
\% Liberal & $50.7 \%$ & $32 \%$ \\
N & 3,417 & \\
\hline
\end{tabular}

Table A2: Comparison between the mTurk sample and the US population on selected socio-economic characteristics. Figures on the US population are from Leider and Roth (2010). 


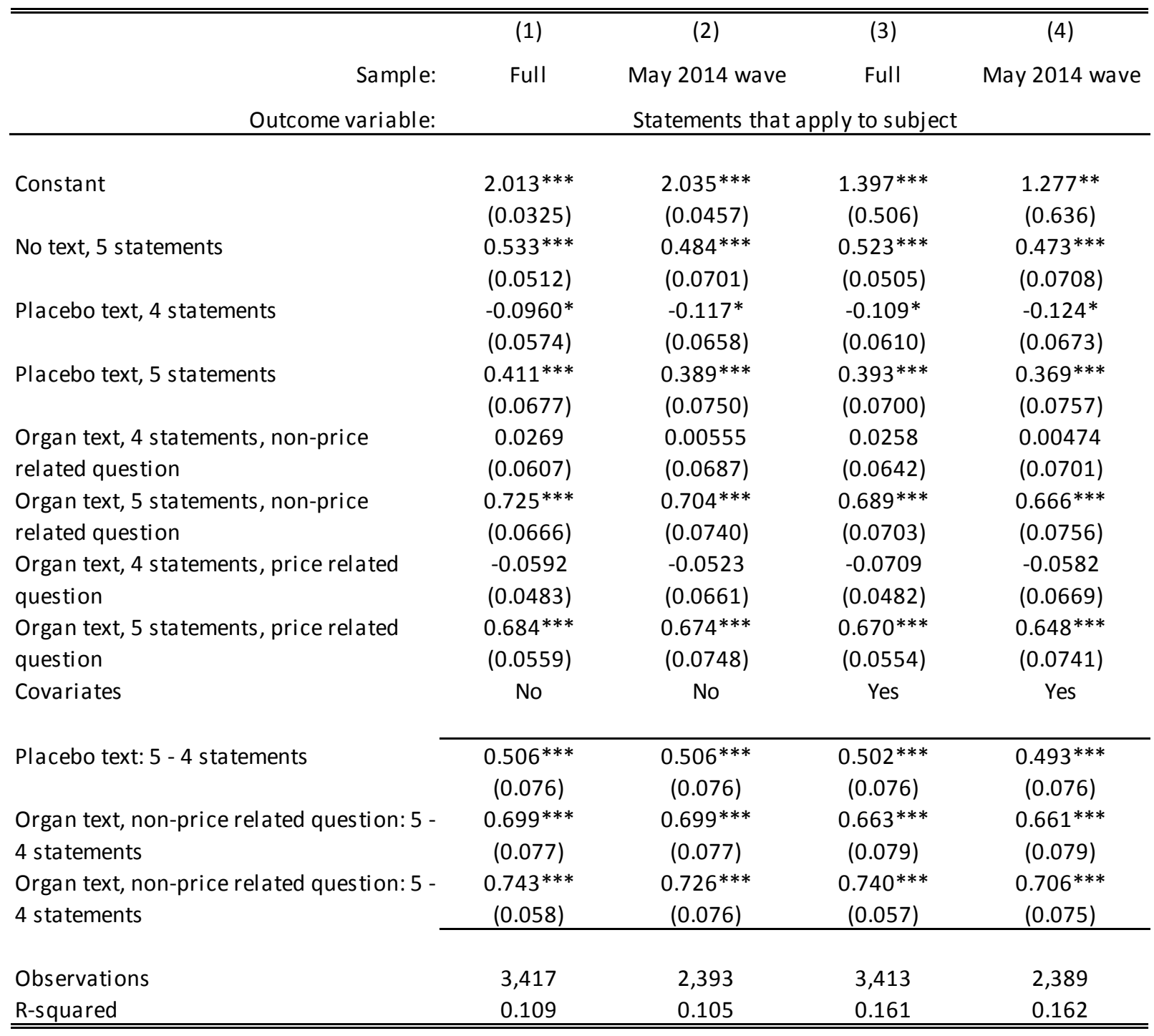

Table A3: Ordinary Least Squares Regression estimates where treatments are disaggregated: control, placebo (flu) text, organ shortage text with question not related to payment for organs, and organ shortage text with question related to payments for organs. The estimates are for the full sample as well as only for the May wave when these more disaggregated conditions were run. Covariates include indicators for gender, job status, income level, educational attainment, relationship status, whether the respondent has children, monthly income, political views, religious beliefs, whether the subject donated to charity or volunteered in the previous two years, state of residence, as well as age in linear and quadratic value. An indicator for the second intervention wave is also added. The specific categories and the distributions in the population are reported in Table S1. Huber-White robust standard errors in parentheses. ${ }^{*} p<0.1 ; * *<<0.05 ; * * * P<0.01$. 


\begin{tabular}{|c|c|c|c|}
\hline & $\begin{array}{c}\text { Baseline support } \\
\text { (no text) }\end{array}$ & $\begin{array}{c}\text { Support after } \\
\text { reading text }\end{array}$ & $\begin{array}{c}\text { Effect of } \\
\text { information (text) }\end{array}$ \\
\hline Overall & $51.8(4.2) * * *$ & $71.3(4.7) * * *$ & $19.5(6.3) * * *$ \\
\hline Men & $57.2(5.8) * * *$ & $72.0(6.1) * * *$ & $14.8(8.5) *$ \\
\hline Women & $45.0(6.2) * * *$ & $70.5(7.1) * * *$ & $25.5(9.4) * * *$ \\
\hline Difference Women - Men & $-12.2(8.5)$ & $-1.5(9.4)$ & $10.8(12.7)$ \\
\hline$<$ College & $50.0(6.1) * * *$ & $78.6(6.6) * * *$ & $28.6(9.0) * * *$ \\
\hline College+ & $53.6(5.9) * * *$ & $63.7(6.5) * * *$ & $10.1(8.7)$ \\
\hline Difference Colleget - <College & $3.6(8.5)$ & $-14.9(9.3)$ & $-18.5(12.6)$ \\
\hline Non-religious & $48.9(5.8) * * *$ & $64.1(6.7) * * *$ & $15.2(8.9) *$ \\
\hline Religious & $55.2(6.0) * * *$ & $79.9(6.4) * * *$ & $23.7(8.8) * * *$ \\
\hline Difference Relig. - Non relig. & $6.3(8.4)$ & $14.8(9.2)$ & $8.5(12.5)$ \\
\hline Monthly income $<\$ 2,500$ & $45.5(4.9)^{* * *}$ & $67.7(5.5) * * *$ & $22.2(7.3) * * *$ \\
\hline Monthly income $>=\$ 2,500$ & $70.4(8.5) * * *$ & $82.6(8.4) * * *$ & $12.2(12.1)$ \\
\hline Difference $>=\$ 2,500-<\$ 2,500$ & $24.9(9.8)^{* *}$ & $14.9(10.2)$ & $-10.0(14.2)$ \\
\hline Liberal & $53.7(6.1) * * *$ & $73.0(6.6)$ & $19.3(8.9) * *$ \\
\hline Moderate & $42.9(7.6)^{* * *}$ & $64.5(7.6) * * *$ & $21.6(11.3) *$ \\
\hline Conservative & $64.4(10.3) * * *$ & $72.9(11.2) * * *$ & $8.5(15.2)$ \\
\hline Difference Lib.-Mod. & $10.8(9.8)$ & $8.5(10.6)$ & $-2.3(14.4)$ \\
\hline Difference Lib.-Cons. & $-10.7(12.0)$ & $0.1(13.0)$ & $10.8(17.7)$ \\
\hline Difference Cons.-Mod. & $21.5(12.8) *$ & $8.4(14.1)$ & $13.1(19.0)$ \\
\hline
\end{tabular}

Table A4. Estimates of treatment effects (expressed as percentages) for support to payments for organs as in equation (1) in the main text, obtained from ordinary least square regressions with the full set of covariates, overall and separated by individual characteristics of interest. Standard errors in parentheses. In a few cases, the reported differences do not precisely correspond with the results of subtracting the reported estimates because of rounding. ${ }^{*} p<0.1 ;{ }^{* *} p<0.05 ;{ }^{* *} p<0.01$. 


\begin{tabular}{|c|c|c|c|c|c|c|}
\hline & $\begin{array}{c}\begin{array}{c}\text { Baseline support } \\
\text { (no text) }\end{array} \\
\end{array}$ & $\begin{array}{c}\text { Support after } \\
\text { reading text }\end{array}$ & $\begin{array}{c}\text { Effect of } \\
\text { information (text) }\end{array}$ & $\begin{array}{c}\text { Baseline support } \\
\text { (no text) }\end{array}$ & $\begin{array}{c}\text { Support after } \\
\text { reading text }\end{array}$ & $\begin{array}{c}\text { Effect of } \\
\text { information (text) }\end{array}$ \\
\hline & \multicolumn{3}{|c|}{ Legalized indoor prostitution } & \multicolumn{3}{|c|}{ Slavery contracts } \\
\hline Overall & $67.3(6.2) * * *$ & $67.4(7.0) * * *$ & $0.2(9.4)$ & $3.5(6.1)$ & $10.4(6.6)$ & $6.9(8.9)$ \\
\hline Men & $77.8(8.7) * * *$ & $95.8(10.0) * * *$ & $18.0(13.3)$ & $-3.3(8.4)$ & $24.3(9.4) * *$ & $27.6(12.7) * *$ \\
\hline Women & $56.1(9.0) * * *$ & $41.0(9.7) * * *$ & $-15.1(13.2)$ & $10.0(8.5)$ & $-2.8(9.2)$ & $-12.8(12.5)$ \\
\hline Difference Women - Men & $-21.7(12.5) *$ & $-54.8(14.0) * * *$ & $-33.1(18.7) *$ & $13.3(12.0)$ & $-27.0(13.2)^{* *}$ & $-40.4(17.8)^{* *}$ \\
\hline$<$ College & $73.2(8.9) * * *$ & $69.1(10.3) * * *$ & $-4.1(13.7)$ & $1.6(8.2)$ & $24.2(9.3) * * *$ & $22.6(12.4) *$ \\
\hline College+ & $61.4(8.8) * * *$ & $65.8(9.5) * * *$ & $4.4(13.1)$ & $6.8(8.7)$ & $-5.3(9.4)$ & $-12.1(12.8)$ \\
\hline Difference Colleget- <College & $-11.8(12.5)$ & $-3.3(14.0)$ & $8.5(18.8)$ & $5.2(12.0)$ & $-29.5(13.3)^{* *}$ & $-34.7(17.8) *$ \\
\hline Non-religious & $81.2(9.5) * * *$ & $94.3(10.5) * * *$ & $13.1(14.2)$ & $6.1(8.9)$ & $5.7(10.2)$ & $-0.4(13.5)$ \\
\hline Religious & $56.8(8.3) * * *$ & $47.3(9.2) * * *$ & $-9.5(12.5)$ & $1.5(8.1)$ & $13.8(8.7)$ & $12.3(11.8)$ \\
\hline Difference Relig. - Non relig. & $-24.5(12.7) *$ & $-47.1(13.9) * * *$ & $-22.6(18.8)$ & $-4.6(12.0)$ & $8.1(13.4)$ & $12.7(17.9)$ \\
\hline Monthly income $<\$ 2,500$ & $66.5(7.5) * * *$ & $65.1(8.4) * * *$ & $-1.4(11.3)$ & $2.0(7.0)$ & $14.0(7.7) *$ & $12.0(10.5)$ \\
\hline Monthly income $>=\$ 2,500$ & $69.1(11.5)^{* * *}$ & $73.0(12.5) * * *$ & $3.9(17.1)$ & $8.3(11.3)$ & $-0.3(12.9)$ & $-8.6(17.1)$ \\
\hline Difference $>=\$ 2,500-<\$ 2,500$ & $2.6(13.7)$ & $7.9(15.2)$ & $5.3(20.5)$ & $6.3(13.3)$ & $-14.3(15.0)$ & $-20.6(20.0)$ \\
\hline Liberal & $76.3(9.6) * * *$ & $82.2(10.0) * * *$ & $5.9(13.9)$ & $8.2(8.8)$ & $1.6(9.8)$ & $-6.6(13.1)$ \\
\hline Moderate & $79.4(10.5) * * *$ & $65.0(12.3) * * *$ & $-14.4(16.1)$ & $5.9(10.4)$ & $25.3(11.5) * *$ & $19.4(15.5)$ \\
\hline Conservative & $15.3(15.0)$ & $24.6(16.6)$ & $9.3(22.4)$ & $-13.2(14.8)$ & $2.6(15.5)$ & $15.8(21.5)$ \\
\hline Difference Lib.-Mod. & $-3.1(14.3)$ & $17.2(15.9)$ & $20.3(21.4)$ & $2.3(13.6)$ & $-23.7(15.1)$ & $-26.0(20.3)$ \\
\hline Difference Lib.-Cons. & $61.0(17.8)^{* * *}$ & $57.6(19.4)^{* * *}$ & $-3.4(26.3)$ & $21.4(17.2)$ & $-1.0(18.4)$ & $-22.4(25.3)$ \\
\hline Difference Cons.-Mod. & $-64.1(18.3) * * *$ & $-40.4(20.7)^{* *}$ & $23.7(27.5)$ & $-19.1(18.1)$ & $-22.7(19.2)$ & $-3.6(26.5)$ \\
\hline
\end{tabular}

Table A5. Estimates of treatment effects (expressed as percentages) for support to legalizing indoor prostitution and slavery contracts, obtained from ordinary least square regressions with the full set of covariates, overall and separated by individual characteristics of interest. Standard errors in parentheses. In a few cases, the reported differences do not precisely correspond with the results of subtracting the reported estimates because of rounding. ${ }^{*} p<0.1 ;{ }^{* *} p<0.05 ;{ }^{* * *} p<0.01$. 


\section{Experimental material}

\section{Organ payments main experiment}

\section{Treatment group:}

\section{PART 1: TEXT}

\section{The Current Situation of the Kidney Transplant System}

In 2013, 99,500 Americans were on the waiting list for a new kidney (1). Yet, only about 16,900 kidney transplant operations were performed in that year. The current average waiting time for a kidney transplant is 4.7 years, up from about 2.9 years only a decade ago (2). A significant increase in the supply of kidneys available for transplantation is required to reduce waiting times.

Kidneys for transplantation come from either deceased or living donors (people who can remain healthy with only one kidney). Finding a compatible kidney is not easy. There are four basic blood types, and tissue matching involves the combination of six proteins. Blood and tissue type determine the likelihood that a kidney will help a recipient in the long run.

Most organ procurements efforts in the U.S. have focused on increasing the pool of altruistic donors, e.g. by expanding living donor inclusion criteria and through organ donor awareness campaigns. In recent years, kidney exchanges-in which pairs of living would-be donors and recipients who prove incompatible look for another pair or pairs of donors and recipients who would be compatible for transplants, cutting their wait time-have become more widespread. In 2013, 590 kidney transplants were performed through these exchanges, accounting for $10 \%$ of live donations and $3.5 \%$ of all kidney transplants, including those with after-death donations.

In an attempt to increase cadaveric organ donations, some nations have enacted the principle of "implied consent", whereby organs from cadavers are assumed to be available for transplant unless, before death, individuals indicate that they don't want their organs to be used. However, even with the capture of all potential deceased donor organs, the gap will not be closed. In 2013, the demand for kidney transplants was 25,500 (3). To satisfy demand, the system would need to generate about 50 deceased donors per million people (pmp). Today, the donation rate is $26 \mathrm{pmp}$ (4).

Another proposal to increase the supply of kidneys is to provide compensation to living donors and/or to the families of individuals who agree in advance to donate a kidney after they die, within a regulated framework. According to some studies (5), a sufficient payment to kidney donors could increase the supply of kidneys by a large percentage. Estimates that consider the risk to donors from transplant surgery, the number of weeks of work lost during the surgery and recovery periods, and the risk of reduction in the quality of life, indicate that with a payment of about US\$15,000 for a kidney (6), the total number of kidney transplants would increase from 16,900 to 23,10 (7).

(1) Unless indicated otherwise, all numbers on the kidney transplant system are from the Organ Procurement and Transplantation Network (OPTN) of the United States.

(2) Using data from OPTN, the average waiting time is computed by dividing the number of patients in the waiting list by the total number of transplants and the number of deaths on the waiting list.

(3) Using data from OPTN, the annual demand is computed as the total number of kidney transplants plus the growth in the waiting list and number of death in the waiting list.

(4) RODaT: The International Online Registry for Organ Donation and Transplantation.

(5) T. Randolph Beard, David L. Kaserman, and RigmarOsterkamp. "The Global Organ Shortage Economic Causes, Human Consequences, Policy Responses," Stanford University Press, 2013.

(6) Becker, Gary S. and Julio J. Elías. "Introducing Incentives in the Market for Live and Cadaveric Organ Donations," Journal of Economic Perspectives, Summer 2007.

(7) Updated calculations following Becker and Elías, 2007. 


\section{PART 2: Comprehension Question}

\section{PART 2: Comprehension question}

Based on the article that you just read, please answer the following question

(1/2 of subjects were assigned the organ payments question)

Please report the price that some studies have identified to potentially compensate kidney donors, and how much they estimate this would increase the supply of kidneys.

(1/2 of subjects are assigned a question randomly chosen from this set)

Please describe what a kidney exchange is, and report approximately what percentage of all kidney transplants was performed through exchange last year.

Please describe what the principle of "implied consent" in organ donation is and, approximately, what the donation rates (donors per million people) from an implied-consent system would need to be to satisfy the demand for kidneys.

Please report approximately how many Americans were on the waiting list for a new kidney, and how many transplants were performed last year.

\section{PART 3: Elicitation of attitudes}

Four statements condition:

Please report below how many of the following statements apply to you

1. For my financial decisions, I usually use the services of a financial advisor.

2. I normally file my tax return on my own, using pre-packaged software or paper forms.

3. I voted or would consider voting for a congressional candidate who supports "pro-choice" policies.

4. I would not support federal legislation aimed at restricting the possession of firearms.

Five statement condition

Please report below how many of the following statements apply to you

1. For my financial decisions, I usually use the services of a financial advisor.

2. I normally file my tax return on my own, using pre-packaged software or paper forms.

3. I voted or would consider voting for a congressional candidate who supports "pro-choice" policies.

4. I would not support federal legislation aimed at restricting the possession of firearms.

5. I would support the introduction of regulated monetary payments for live organ donors and for the families of deceased organ donors.

(Note: the order of the statements was randomized) 


\section{Placebo condition}

\section{PART 1: TEXT}

\section{The flu: basic facts and prevention guidelines}

Influenza (flu) is a contagious respiratory illness caused by influenza viruses (1). Symptoms include fever or feeling feverish/chills, cough, sore throat, runny or stuffy nose, muscle or body aches, headaches, and fatigue (2).Especially older people, young children, and people with certain health conditions are at high risk for serious flu complications.

Most experts believe that flu viruses spread mainly by droplets made when people with flu cough, sneeze or talk. Less often, a person might also get the flu by touching a surface or object that has flu virus on it and then touching their own mouth, eyes or possibly their nose. You may be able to pass on the flu to someone else before you know you are sick, as well as while you are sick (3). Most healthy adults may be able to infect others beginning 1 day before symptoms develop and up to 5 to 7 days after becoming sick.

The single best way to prevent the flu is to get a flu vaccine each season (4). Commonly available are Traditional flu vaccines (5) made to protect against three different flu viruses (two influenza $A$ viruses (H1N1 and H3N2) and one influenza B virus), called "trivalent" vaccines, and those that protect against four different flu viruses (two influenza A viruses and two influenza B viruses), called "quadrivalent" vaccines.

Yearly flu vaccination should begin soon after flu vaccine is available, ideally by October. However, getting vaccinated even later can be protective, as long as flu viruses are circulating. Although seasonal influenza outbreaks can happen as early as October, most of the time influenza activity peaks in January or later (6). Since it takes about two weeks after vaccination for antibodies to develop in the body that protect against influenza virus infection, it is best that people get vaccinated so they are protected before influenza begins spreading in their community.

Everyone who is at least 6 months of age should get a flu vaccine (7). This recommendation has been in place since February 24, 2010 when CDC's Advisory Committee on Immunization Practices (ACIP) voted for "universal" flu vaccination in the United States to expand protection against the flu to more people. It is especially important for some people to get vaccinated, including people who are at high risk of developing serious complications (like pneumonia) if they get sick with the flu, and people who live with or care for others who are at high risk of developing serious complications.

(1) Unless indicated otherwise, information in this note is from the Center for Disease Control website: http://www.cdc.gov/flu/about/disease/index.htm

(2) Eccles, R. "Understanding the symptoms of the common cold and influenza". Lancet Infect Dis, 2005.

(3) Brankston G, Gitterman L, Hirji Z, Lemieux C, Gardam M. "Transmission of influenza A in human beings". Lancet Infect Dis, 2007.

(4) WHO position paper: influenza vaccines WHO weekly Epidemiological Record 19 August 2005.

(5) Couch, RB. "Seasonal Inactivated Influenza Virus Vaccines". Vaccine, 2008.

(6) "The Flu Season". U.S. Centers for Disease Control and Prevention.

(7) "Who Should Get Vaccinated Against Influenza”. U.S. Centers for Disease Control and Prevention. 


\section{PART 2: Question}

Based on the article that you just read, please answer the following question (All subjects in the placebo group are assigned the same question)

Please describe the main symptoms generated by the flu.

\section{PART 3: Elicitation of attitudes}

Four statements condition:

Please report below how many of the following statements apply to you

1. For my financial decisions, I usually use the services of a financial advisor.

2. I normally file my tax return on my own, using pre-packaged software or paper forms.

3. I voted or would consider voting for a congressional candidate who supports "pro-choice" policies.

4. I would not support federal legislation aimed at restricting the possession of firearms.

Five statement condition

Please report below how many of the following statements apply to you

1. For my financial decisions, I usually use the services of a financial advisor.

2. I normally file my tax return on my own, using pre-packaged software or paper forms.

3. I voted or would consider voting for a congressional candidate who supports "pro-choice" policies.

4. I would not support federal legislation aimed at restricting the possession of firearms.

5. I would support the introduction of regulated monetary payments for live organ donors and for the families of deceased organ donors.

(Note: the order of the statements was randomized) 


\section{Prostitution condition}

\section{PART 1: TEXT}

\section{Prostitution in the United States}

Prostitution in the United States is illegal, except in some rural counties in Nevada. The prohibition is enforced in different forms, such as incarcerating sex workers, charging individuals engaging in prostitution with a felony, or implementing prostitution diversion programs. Prostitution, however, is present in most parts of the country, in various forms. In the last 15 years, the American prostitution market has shifted from a primarily outdoor (street-based) to an indoor market (massage parlors, escort agencies, and much of the online activity) (1). The prostitution trade is estimated to gross over \$14 billion a year in the US (2). A 2004 poll reports that 30\% of single men over the age of 30 have paid for sex in the US (3).

Disease transmission and victimization risks are associated with sex markets. The 1992 National Health and Social Life Survey (NHSLS) reports that $22.9 \%$ of female prostitutes report they have had gonorrhea relative to $4.7 \%$ of non-prostitute females. The spread of this and other sexually transmitted diseases is a public health concern (4). Sex market-related violence is also common. One study finds that $68 \%$ of women engaged in street-level prostitution have been raped by clients and another reports that one third of all serial murder victims are prostitutes (5).

To reduce the potential costs associated with prostitution, some analysts have proposed decriminalizing indoor sex work, but few governments have been willing to experiment with the policy. It has been argued that indoor prostitution typically involves less exploitation, less risk of violence, more control over working conditions, more job satisfaction, and higher self-esteem (6). Street prostitution has higher rates of gonorrhea (7), rape and sexual assault than indoor prostitution (8).

A recent study (9) finds that the decriminalization of indoor prostitution in Rhode Island in 2003 caused both forcible rape offenses and gonorrhea incidence to decline for the overall population. From 2004 to 2009 , reported rape offenses decreased by $31 \%$ and the number of cases of female gonorrhea decreased by $39 \%$.

(1) Cunningham, Scott and Todd D. Kendall. 2001. "Prostitution 2.0: The Changing Face of Sex Work," Journal of Urban Economics.

(2) Havoscope. 2013. http://www.havocscope.com/prostitution-revenue-by-country/.Technical report.

(3) Langer, Gary, Cheryl Arnedt and Dalia Sussman. 2004. \Primetime Live Poll: American Sex Survey.".

(4) National Institutes of Health, 2001.

(5) Farley, Melissa and Vanessa Kelly. 2000. "Prostitution: a critical review of the medical and social sciences literature," Women and Criminal Justice.

(6) Weitzer, Ronald. 2005. "New Directions in Research on Prostitution," Crime, Law \& Social Change.

(7) Potterat, John J., Richard B. Rothenberg and Donald C. Bross. 1979. "Gonorrhea in street prostitutes: epidemiologic and legal implications," Sexually Transmitted Diseases.

(8) Church, Stephanie, Marion Henderson, Marina Barnard and Graham Hart. 2001. "Violence by clients towards female prostitutes in different work settings: questionnaire survey," British Medical Journal.

(9) Cunningham, Scott and Shah, Manisha. 2014. "Decriminalizing Indoor Prostitution: Implications for Sexual Violence and Public Health," NBER Working Papers, National Bureau of Economic Research. 


\section{PART 2: Question}

Based on the article that you just read, please answer the following question

Please report the declines in rape offenses and cases of female gonorrhea estimated in the study described in the reading.

\section{PART 3: Elicitation of attitudes}

Four statements condition:

Please report below how many of the following statements apply to you

1. For my financial decisions, I usually use the services of a financial advisor.

2. I normally file my tax return on my own, using pre-packaged software or paper forms.

3. I voted or would consider voting for a congressional candidate who supports "pro-choice" policies.

4. I would not support federal legislation aimed at restricting the possession of firearms.

Five statement condition

Please report below how many of the following statements apply to you

1. For my financial decisions, I usually use the services of a financial advisor.

2. I normally file my tax return on my own, using pre-packaged software or paper forms.

3. I voted or would consider voting for a congressional candidate who supports "pro-choice" policies.

4. I would not support federal legislation aimed at restricting the possession of firearms.

5. I would support the legalization of indoor prostitution within a regulated framework.

(Note: the order of the statements was randomized) 


\section{Slavery condition}

\section{PART 1: TEXT}

\section{Slavery in the modern world}

Slavery is a system under which people are treated as property to be bought and sold, and are forced to work (1). Historically, slavery was institutionally recognized by most societies; in more recent times, slavery has been outlawed in all countries (2).

Slavery is officially illegal in all countries, but according to the International Labor Organization (ILO) 20.9 million men, women and children around the world are in slavery (3). Mauritania was the last jurisdiction to officially outlaw slavery (in 1981/2007), but about $10 \%$ to $20 \%$ of its population is estimated to live in slavery (4).

Contemporary slavery takes various forms and affects people of all ages, gender and races. Under contemporary slavery people suffer mental or physical threat; mental or physical abuse or the threat of abuse; dehumanized treatment, they are physically constrained or have restrictions placed on their freedom of movement (5).

Although no country has experimented this, could the introduction of an institutional framework that would legalize slavery (e.g., through "slavery contracts") improve the living conditions and opportunities of "de facto" slaves?

In the book Time on the Cross: The Economics of American Negro Slavery (1974) (6), Robert Fogel and Stanley Engerman show that following emancipation and the end of the Civil War, the life expectancy of freedmen declined by ten percent, and their illnesses increased by twenty percent compared to slavery times. Fogel and Engerman asserted that slavery had a reciprocal economic benefit for slave owners and slaves. They wrote, "[S]lave owners expropriated far less than generally presumed, and over the course of a lifetime a slave field hand received approximately ninety percent of the income produced." The authors estimated the value of housing, clothing, food and other benefits received by the slaves and argued that they lived as well in material terms as did free urban laborers; life was equally difficult for both classes of individuals.

(1) Laura Brace (2004). The Politics of Property: Labour, Freedom and Belonging. Edinburgh University Press. pp. 162

(2) "Historical survey: Slave-owning societies." Encyclopædia Britannica.

(3) "Forced labour - Themes." International Labor Organization. Ilo.org. Retrieved 2014-09-01.

(4) "Mauritanian MPs pass slavery law." BBC, News.bbc.co.uk, 9 August 2007.

(5) Bales, Kevin (1999). Disposable People: New Slavery in the Global Economy. University of California Press.

(6) Fogel, Robert W. and Stanley L. Engerman (1974). "Time on the Cross. The Economics of American Negro Slavery." Boston: Little, Brown and Company. 


\section{PART 2: Question}

Based on the article that you just read, please answer the following question

By how much did the life expectancy of freedmen declined, following the emancipation and the end of the Civil War and compared to slavery times according to the study described in the reading?

\section{PART 3: Elicitation of attitudes}

Four statements condition:

Please report below how many of the following statements apply to you

1. For my financial decisions, I usually use the services of a financial advisor.

2. I normally file my tax return on my own, using pre-packaged software or paper forms.

3. I voted or would consider voting for a congressional candidate who supports "pro-choice" policies.

4. I would not support federal legislation aimed at restricting the possession of firearms.

Five statement condition

Please report below how many of the following statements apply to you

1. For my financial decisions, I usually use the services of a financial advisor.

2. I normally file my tax return on my own, using pre-packaged software or paper forms.

3. I voted or would consider voting for a congressional candidate who supports "pro-choice" policies.

4. I would not support federal legislation aimed at restricting the possession of firearms.

5. I would support the introduction of a legal framework that allows for regulated slavery contracts.

(Note: the order of the statements was randomized) 
Questions common to all treatments, placebo and control conditions

What is your age in years?

\section{Are you \\ Male \\ Female}

What is your state of residence?

What is your race?

White/Caucasian

African American

Hispanic

Asian

Other (specify)

What is your relationship status?

Single

Unmarried but in a relationship

Married

Separated/Divorced

Other

What is your parental status?

I have children

I do not have children

What is your highest degree of education attained?

Completed primary school

Some high school

Completed high school

Some university

Completed undergraduate university degree

Postgraduate

What is your current employment status?

Private Employee

Public Employee

Self-employed/Entrepreneur

Unemployed

Housekeeper

Student

Retired 
Approximately what is your monthly income?

I am not currently earning any income

Less than $\$ 1.500$

Between $\$ 1.500$ and $\$ 2.500$

Between $\$ 2.500$ and $\$ 5.000$

More than $\$ 5.000$

Have you donated money or volunteered time to a charitable organization in the past $\mathbf{2}$ years?

No

Yes

What is your religion?

Atheist/Agnostic

Christian

Jewish

Muslim

Other

What are your political views?

Conservative

Liberal

Moderate

Other

What you think the main objective of this survey was? 